\title{
The association between pregnancy-specific anxiety and preterm birth: a cohort study
}

\author{
Zahra Bostani Khalesi ${ }^{1}$, Mahshid Bokaie ${ }^{2}$
}

1. Nursing and Midwifery School, Guilan University of Medical Sciences, Rasht, Iran.

2. Research Center for Nursing and Midwifery Care, Shahid Sadoughi University of Medical Sciences, Yazd, Iran.

\begin{abstract}
Background: Antenatal anxiety may have long-term negative effects on pregnancy outcome. Antenatal anxiety can also be detrimental to maternal health during pregnancy. Therefore, this study aimed to determine the association between pregnancy-specific anxiety and preterm birth in pregnant women.

Methods: This prospective cohort study was conducted on 208 pregnant women who were referred to the prenatal clinic of Al-Zahra hospital in Rasht. Sampling was conducted through convenient (simple) method. Data gathering tools were a demographic characteristics questionnaire and pregnancy-specific anxiety scale. The data were analyzed using SPSS version 19. General Linear Model (GLM)-Repeated Measures test were used to study variations in anxiety along pregnancy period and tested levels of significance among inter-trimester anxiety scores.

Results: Results of the study showed that change in pregnancy-specific anxiety is significantly associated with preterm birth among participants in this study. Second trimester pregnancy-specific anxiety was not associated with preterm birth, but third trimester pregnancy-specific anxiety was associated with preterm birth.

Conclusion: According to the results of this study, third trimester pregnancy-specific anxiety was associated with preterm birth. Therefore, the health care providers should pay special attention to pregnancy-specific anxiety.

Keywords: Pregnancy-specific anxiety, preterm birth, pregnancy outcome.

DOI: https://dx.doi.org/10.4314/ahs.v18i3.14

Cite as: Khalesi ZB, Bokaie M. The association between pregnancy-specific anxiety and preterm birth: a cohort study. Afri Health Sci. 2018;18(3): 569-575. bttps://dx.doi.org/10.4314/abs.v18i3.14
\end{abstract}

\section{Introduction}

Preterm birth is commonly defined as delivery that occurs at a gestational age less than 37 weeks $^{1}$. Preterm birth is a significant public health problem leading to increased neonatal morbidity and mortality and entailing substantial social and economic costs in the developed world ${ }^{2}$. It is associated with 8 to $24 \%$ of pregnancies3. In most

\section{Corresponding author: \\ Mahshid Bokaie, \\ Research Center for Nursing and \\ Midwifery Care, Shahid Sadoughi \\ University of Medical Sciences, Yazd, Iran. \\ Email: mah_bokaie@yahoo.com}

countries, the rates of preterm birth have been increasing in recent decades and this represents a primary obstacle to the World Health Organization's Millennium Development Goal 4, which is to reduce childhood mortality ${ }^{4}$. Predisposing factors of preterm birth are still not obviously recognized ${ }^{5}$. However, some studies have shown maternal mental factors to play some role ${ }^{2}$. Therefore, it is important to identify modifiable risk factors that may lead to the primary prevention of preterm birth.

Pregnancy is often viewed as a very positive time in a woman's life 6 . This despite the fact that this period is also characterized by many ongoing changes ${ }^{7}$. Feelings of anxiety across pregnancy are relatively common, with about $10-15 \%$ of all pregnant women experiencing some level of anxiety or anxiety during this major transitional phase in one's life ${ }^{8}$. Research suggests anxiety disorders are

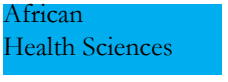

(C) 2018 Khalesi et al. Licensee African Health Sciences. This is an Open Access article distributed under the terms of the Creative commons Attribution License (https://creativecommons.org/licenses/BY/4.0), which permits unrestricted use, distribution, and reproduction in any medium, provided the original work is properly cited. 
more common than depressive disorders in the perinatal period. Pregnancy-specific anxiety ${ }^{1}$ is defined as a mental state of a pregnant woman whose concerns are specific to the pregnancy itself, such as fears regarding the pregnancy, delivery, and health of the child ${ }^{9}$. A woman's ability to adapt to the changes and challenges of pregnancy is unique, therefore P-SA can vary from woman to woman ${ }^{6}$. Most studies reported varied prevalence rate from different parts of the world and the majority of them explored general anxiety than P-SA ${ }^{10}$. Assessment of general anxiety during pregnancy may underestimate pregnancy specific anxiety ${ }^{11}$. Only few studies have systematically assessed the specific fears and worries related to pregnancy and the structure of P-SA ${ }^{12}$. Previous studies reported that $54 \%$ low risk pregnant women had P-SA and it varied at different trimesters of pregnancy with a U pattern of high anxiety during first and third ${ }^{13}$. Elevated untreated anxiety in pregnancy may impact negatively on the developing baby ${ }^{14}$.

Findings of Ding et al. ${ }^{15}$ and Behrman et al. ${ }^{16}$ revealed that P-SA was significantly associated with an increased risk for preterm birth and remained significant regard- less of the timing of anxiety assessment. While much is known about the relationship between P-SA and PB, there is debate about the point in pregnancy at which P-SA has the greatest effect on length of gestation. Although some research suggests that the critical time is during the second trimester, other evidence points to third trimester as more predictive of preterm birth and length of gestation ${ }^{17}$. Cross-sectional measurements of P-SA that are prevalent in the literature prevent firm conclusions regarding the time when P-SA has the greatest effect on birth outcomes ${ }^{18}$. This gap also prevents understanding of the relationship between change in P-SA and length of gestation. The purpose of this study was to investigate longitudinally the association of P-SA with PB.

\section{Methods}

This prospective cohort study was conducted on 208 pregnant women who referred to the prenatal clinic of Al-Zahra hospital in Rasht to receive prenatal care. The cohort was limited to only those women with complete data for second and third trimester interviews and recorded gestational age, resulting in a sample size of 208 (Figure 1).

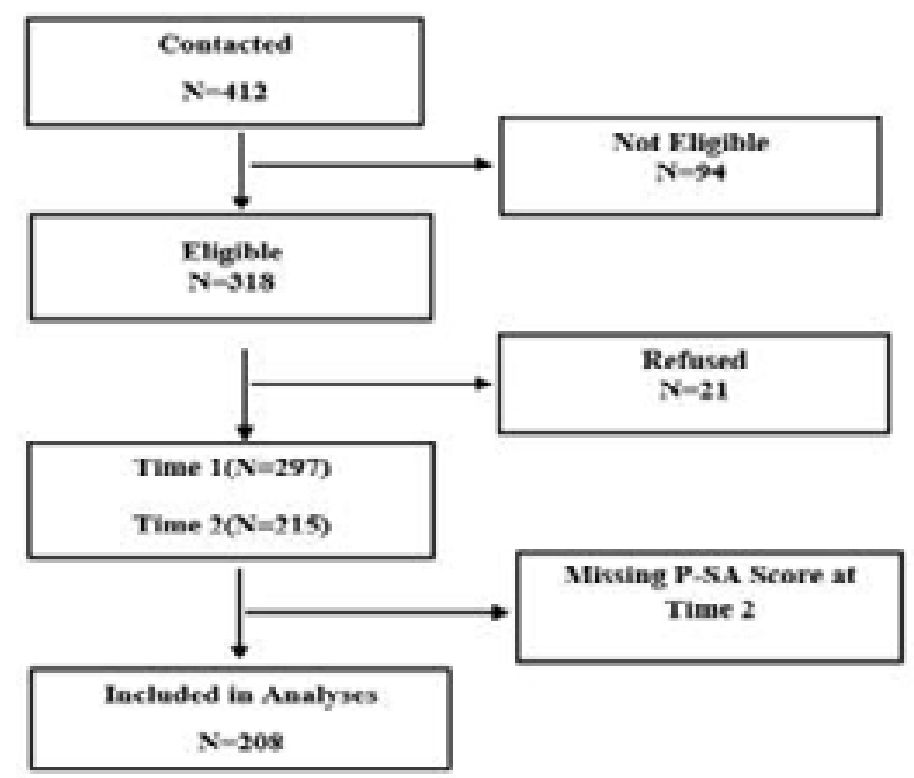

Figure 1: Consort diagram 
Sampling was conducted through convenient (simple) method until the intended sample size was reached. The inclusion criteria were 18 to 35 years old, being Iranian, having singleton pregnancy, having a gestational age of 8 to 12 weeks, not smoking cigarettes or hookah, not consuming alcohol, not using any drugs, and not having a history of mental illnesses or known depression and anxiety at any other periods of life. The exclusion criteria were having a history of preterm delivery, having a history of abortion, stillbirths or infertility, having any diagnosed complications of the pregnancy, such as incompetent cervix, history of having any cardiovascular, respiratory, hematologic, renal, liver, infectious and endocrine diseases and history of diabetes or hypertension. To ensure a consistent approach in dating pregnancy we was used ultrasound furthermore the $\mathrm{LMP}^{2}$. Of the 208 women, 119 (57.21\%) had an ultrasound done in the first trimester and $89(42.79 \%)$ had an ultrasound in the second trimester.

Data gathering tools were a demographic and obstetric characteristics questionnaire (including age, job, and educational status, number of deliveries and history of preterm deliveries, abortions, stillbirths and infertility), pregnancy-specific anxiety scale to assess P-SA. The validity of the demographic, social and obstetric characteristics questionnaire was approved using content validity; meaning that the primary version of the questionnaire was developed after reviewing the most recent books and articles about the research and after modification, was distributed among 12 academic members of the Guilan University of Medical Sciences. Then applying their opinions and recommendations, the final version of the questionnaire was developed. Pregnancy-specific anxiety scale is a standardized questionnaire to assess P-SA. It measures the intensity of a woman's anxiety in four main areas of pregnancy and childbirth anxiety. Pregnancy-specific anxiety scale has 40 items self-report questionnaire on a fivepoint Likert scale with a maximum score of $200^{19}$. The first part deals with anxiety about being pregnant with 16 items to explore anxiety related to pregnancy. The second part is related to anxiety of childbirth with 10 items. The third part with eight questions related to anxiety about breastfeeding and the fourth part with 6 questions related to anxiety about newborn care. The reliability of the pregnancy-specific anxiety scale was established using the split half method and the reliability coefficient obtained was 0.82 which indicated that the tool was reliable. The face and content validity of the pregnancy-specific anxiety scale was established to review by 5 psychologists and psychiatrists. After selecting eligible pregnant women, and completely explaining the aims of the study for them, written informed consent was obtained from all the participants.

Also the participants were assured that they could leave the study at any desired time without any changes in their prenatal care. Then demographic and obstetric characteristics questionnaire was filled by the participants. All the participants were followed-up until the end of their pregnancy to determine preterm birth. So mother's phone numbers were recorded. Initially, pregnant women who met the inclusion criteria and volunteered were recruited to the study as convenient sample. Each pregnant woman was contacted at their 8-12 weeks asked to self-rate their anxiety using a pregnancy-specific anxiety scale. They were followed up throughout their pregnancy and postpartum period. The P-SA were assessed at second trimester (20-28 weeks) and third trimester (30 -38 weeks). The assistants of the researchers were present at the time of delivery to record the time of delivery and observe and record the pregnancy and neonatal outcomes. To prevent any bias in data collection, assistants were not aware of mothers' depression condition. Deliveries that were occurring sooner than the $37^{\text {th }}$ week of the pregnancy were considered preterm birth. To describe the characteristics of the studied participants descriptive statistics, distribution (mean and standard deviation), and frequency distribution was used. General Linear Model (GLM)-Repeated Measures test were used to study variations in anxiety along pregnancy period and tested levels of significance among inter-trimester anxiety scores. The data were analyzed using SPSS version 19 with two-tailed significance level of less than 0.05 .

\section{Results}

Results of the study showed that the mean age of the participants was $26.6 \pm 2.1$ years old, the highest frequencies belonged to housewives $(78.36 \%)$, diploma educational level $(47.11 \%)$, being nulliparous $(50.96 \%)$, and wanted pregnancy $(62.98 \%)$. The study revealed that nulliparous status is an influencing factor for the high prevalence of P-SA. 
Four areas of P-SA such as anxiety of being pregnant, anxiety about childbirth, anxiety about breast feeding and anxiety about newborn care were analyzed separately. With advancing gestational age, P-SA scores significantly increased. The highest prevalence of $(58.65 \%)$ moderate levels of P-SA was reported in second trimesters. The highest prevalence of $(53.84 \%)$ severe degree of P-SA was reported during the third trimester. The inter-trimester differences of means were statistically tested using GLM test. The value of $(F=321.47)$ shows that P-SA across the two trimesters differed significantly at $0.01 \mathrm{lev}$ els.

Our results reveal that the highest prevalence of mild 66.82 was reported anxiety of being pregnant during the third trimester. Most (87.98\%) of the pregnant women had moderate anxiety about childbirth during the third trimester. Inter-trimester differences in the anxiety of being pregnant were tested statistically using GLM test. The value of $\mathrm{F}=375.81$ shows that in each trimester anxiety about childbirth differed significantly at 0.001 levels.

Also, most (78.36\%) of the pregnant women had a moderate level of anxiety about breastfeeding during the third trimester. During third trimester, women rated the highest levels $(71.15 \%)$ of severe degree anxiety about new born care.

Change in P-SA is significantly associated with preterm birth among participants in this study. Second trimester P-SA was not associated with preterm birth, but third trimester P-SA was associated with preterm birth (Table 1).

\section{Table 1. Prevalence and level of significance of pregnancy-specific anxiety and four areas across trimesters 2,3 of pregnancy.}

\begin{tabular}{|l|l|l|l|l|l|l|}
\hline \multicolumn{1}{|c|}{ Variables } & Mild & Moderate & Severe & Mean & SD & GLM-test \\
\hline Pregnancy-specific anxiety (T2) & 25 & 58.65 & 16.35 & 98.21 & 12.02 & F $=321.47$, \\
\hline Pregnancy-specific anxiety (T3) & 10.57 & 35.57 & 53.86 & 103.4 & 9.572 & p $<0.01$ \\
\hline Anxiety of being pregnant (T2) & 63.46 & 13.94 & 22.6 & 50.23 & 6.392 & F $=183.63$, \\
\hline Anxiety of being pregnant(T3) & 66.82 & 12.98 & 20.2 & 49.38 & 5.656 & $p<0.1$ \\
\hline Anxiety about childbirth (T2) & 8.17 & 77.88 & 13.95 & 34.16 & 2.741 & $F=375.81$, \\
\hline Anxiety about childbirth (T3) & 2.88 & 9.13 & 87.99 & 65.41 & 2.344 & $P<0.001$ \\
\hline Anxiety about Breast Feeding (T2) & 4.8 & 47.11 & 48.09 & 13.47 & 2.607 & $F=42.79$, \\
\hline Anxiety about Breast Feeding (T3) & 3.36 & 78.36 & 18.28 & 14.92 & 3.236 & $P<0.05$ \\
\hline Anxiety about New born Care (T2) & 9.13 & 41.84 & 49.03 & 39.60 & 2.715 & $F=38.24$, \\
\hline Anxiety about New born Care (T3) & 7.21 & 21.63 & 71.15 & 51.71 & 2.371 & $P<0.05$ \\
\hline
\end{tabular}

*T2, 3: Trimester 2, Trimester 3

*GLM: General Linear Model 
Both multiparous and nulliparous mothers reported high third trimester PSA compared to second trimesters. Nulliparous pregnant women reported higher PSA across second and third trimesters with the highest during third trimester, PSA (mean 131.86) compared to parous women (mean 98.16). GLM test revealed significant levels at 0.05 for score differences among nulliparous and parous pregnant women. This indicates that pregnancy-specific anxiety is higher among nulliparous women (Table 2).

Table 2. The Mean, SD and level of significance of mean scores of P-SA with nulliparous and parous pregnant women.

\begin{tabular}{|c|c|c|c|c|l|}
\hline \multirow{3}{*}{ Variable } & \multicolumn{2}{|c|}{$\begin{array}{c}\text { Nulliparous pregnant } \\
\text { women (106) }\end{array}$} & \multicolumn{2}{|c|}{$\begin{array}{c}\text { Parous pregnant } \\
\text { women (102) }\end{array}$} & \multirow{2}{*}{ GLM-test } \\
& Mean & SD & Mean & SD & \\
\cline { 2 - 5 } & 131.86 & 8.011 & 98.16 & 8.92 & $F=162.69$ \\
\hline Trimester-2 & 147.32 & 9.172 & 102.23 & 3.29 & $P<0.05$ \\
\hline Trimester-3 & 142.29 & \\
\hline
\end{tabular}

*GLM: General Linear Model

\section{Discussion}

P-SA varies from trimester to trimester ${ }^{20}$. The level of anxiety a pregnant woman experiences affects the outcome of pregnancy. An observational, analytical cross-sectional study among 174 third trimester pregnant women in Spain revealed that pregnant women's anxiety levels were higher than average levels in the general population ${ }^{21}$. Evidence also established the relationship between high levels of P-SA and preterm birth ${ }^{22,23}$. The current study reported very high prevalence of severe degree of the third trimester P-SA during the third trimester. Previous studies also reported high P-SAscore among pregnant women $^{17,20,24}$. It has been reported that women with a high P-SA tend to have more preterm birth ${ }^{25}$. The study revealed that nulliparous status is an influencing factor for the high prevalence of P-SA. These findings are consistent with previous studies ${ }^{22}$.

The highest prevalence of anxiety about childbirth was reported during the third trimester. Throughout the course of pregnancy, high levels of anxiety about childbirth were observed in the third trimester with low prevalence in second trimester ${ }^{26}$. The current finding is consistent with similar findings in other studies ${ }^{27}$. Nulliparous women reported higher childbirth anxiety than parous mothers; these results are consistent with similar previous studies $^{28,29}$. So current study recommends that the prenatal care should focus on measures to reduce pregnancy specific anxiety, particularly among nulliparous women which would reduce preterm birth.

African Health Sciences Vol 18 Issue 3, September, 2018

\section{Conclusion}

The findings from this study have significant implications for the health care provider. Antenatal anxiety must be considered as a top priority to reduce adverse pregnancy outcomes such as preterm birth. A formal antenatal screening for P-SA should be a part of routine antenatal check up to identify the high risk groups of pregnant women with pregnancy anxiety and fear. The findings of the present study suggest the necessity of implementing interventions to reduce P-SA and thereby positively influence birth outcomes. In the present study, we measured P-SA at the second and third trimester which provides a very limited assessment of the psychosocial health of the pregnant women throughout the pregnancy.

A larger longitudinal cohort study, with multiple measures of stress, depression, and cortisol levels, as well as a measure of P-SA may add new knowledge and enhance our understanding of the relationship between stress, depression, P-SA, cortisol levels and preterm birth.

\section{Acknowledgments}

The authors would like to thank all couples participating, authorities, and nurses and midwives in the Al-Zahra hospital, who helped us in conducting this research.

\section{Conflict of interest}

The authors declare that they have no conflicts of interest. 


\section{References}

1. Yang S, Platt RW, Kramer MS. Variation in Child Cognitive Ability by Week of Gestation among Healthy Term Births. American Journal of Epidemiology. 2010. PubMed

2. Berkowitz GS, Papiernik E. Epidemiology of preterm birth. Epidemiologic reviews. 1993; 15(2):414-443. PubMed

3. Bostani Khalesi Z, Abedinzadeh M, Yaghoubi Y. The Effect of Massage on the Arterial Blood Oxygen Saturation in Neonates with Respiratory Distress Syndrome. Journal of Sabzevar University of medical science. 2011; 18(1): 6-12.

4. Dailey DE, Humphreys JC, Rankin SH, Lee KA. An Exploration of Lifetime Trauma Exposure in Pregnant Low-income African American Women. Maternal and Child Health Journal. 2011; 15(3):410-418. PubMed

5. Bostani Khalesi Z, Niknami M, Ghorbani A. Prediction of hypertension by anthropometric parameters in prim gravidae. ARYA Atheroscler. 2012. 8(Special Issue in National Hypertension Treatment): S169-S173.

6. Arnold A, Lewis J, Maximovich A, Ickovics J, Kershaw T. Antecedents and consequences of caregiving structure on young mothers and their infants. Maternal and Child Health Journal. 2011; 15(7):1037-1045. PubMed

7. Coussons-Read ME, Lobel M, Carey JC, Kreither MO, D’Anna K, Argys L, Cole S. The occurrence of preterm delivery is linked to pregnancy-specific dianxiety andelevated inflammatory markers across gestation. Brain, Behavior, and Immunity. 2012; 26(4):650-659. PubMed

8. Alderdice F, Lynn F, Lobel M. A review and psychometric evaluation of pregnancy-specific anxiety measures. Journal of Psychosomatic Obstetrics \& Gynecology. 2012; 33(2):62-77. PubMed

9. Bussieres EL, Tarabulsy GM, Pearson J, Tessier R, Forest JC, Giguére Y. Maternal prenatal stress and infant birth weight and gestational age: a meta-analysis of prospective studies. Developmental Rev. 2015; 36: 1179- 1199. PubMed

10. Davis EP, Glynn LM, Waffarn F, Sandman CA. Prenatal maternal anxiety programs infant anxiety regulation. Journal of Child Psychology and Psychiatry. 2011; 52(2):119129. PubMed

11. Dole N, Savitz DA, Siega-Riz AM, Hertz-Picciotto I, McMahon MJ, Buekens P. Psychosocial factors and preterm birth among African American and White women in central North Carolina. American Journal of Public Health. 2004; 94(8):1358-1365. PubMed

12. Kalantaridou SN, Zoumakis E, Makrigiannakis A,
Lavasidis LG, Vrekoussis T, Chrousos GP. Corticotropin-releasing hormone, anxiety and human reproduction: an update. Journal of Reproductive Immunology. 2010; 85(1):33-39. PubMed

13. Dunkel Schetter C, Tanner L. Anxiety, depression and anxiety in pregnancy: implications for mothers, children, research, and practice. Current Opinion in Psychiatry. 2012; 25(2):141-148. PubMed

14. Gennaro S, Shults J, Garry DJ. Anxiety and preterm labor and birth in Black women. Journal of obstetric, gynecologic, and neonatal nursing: JOGNN / NAACOG. 2008; 37(5):538-545. PubMed

15. Ding XX, Wu YL, Xu SJ, Zhu RP, Jia XM, Zhang SF, et al. Maternal anxiety during pregnancy and adverse birth outcomes: a systematic review and meta-analysis of prospective cohort studies. I Affect Disord. 2014; 159: 103110. PubMed

16. Behrman R and Butler A. Preterm Birth: Causes, Consequences, and Prevention. Washington (DC): National Academies Press (US); 2007. PubMed

17. Littleton HL., Breitkopf CR., Berenson A. B. Correlates of anxiety symptoms during pregnancy and association with perinatal outcomes: a meta-analysis. American Journal of Obstetrics and Gynecology. 2007; 196 (5). 424-432. 18. Glynn LM, Schetter CD, Hobel CJ, Sandman CA. Pattern of perceived anxiety and anxiety in pregnancy predicts preterm birth. Health psychology: official Journal of the Division of Health Psychology, American Psychological Association. 2008; 27(1):43-51. PubMed

19. Spielberger CD. State-trait anxiety inventory: A comprehensive bibliography. Consulting Psychologists Press, Palo Alto, CA; 1989.

20. Orr ST, Reiter JP, Blazer DG, James SA. Maternal Prenatal Pregnancy-Related Anxiety and Spontaneous Preterm Birth in Baltimore, Maryland. Psychosomatic Medicine. 2007; 69(6):566-570.

21. García Rico MA., Rodríguez AJM., Díez SMU., Real MCM. Análisis de la relación entre riesgo gestacional y ansiedad materna. Progresos de Obstetricia y Ginecología. 2010; 53: 273-279.

22. Pearce BD, Grove J, Bonney EA, Bliwise N, Dudley DJ, Schendel DE, Thorsen P. Interrelationship of Cytokines, Hypothalamic-Pituitary-Adrenal Axis Hormones, and Psychosocial Variables in the Prediction of Preterm Birth. Gynecologic and Obstetric Investigation. 2010; 70(1):4046. PubMed

23. Lynn FA, Alderdice FA, Crealey GE, McElnay JC. As- 
sociations between maternal characteristics and pregnancy-related anxiety among low-risk mothers: An observational cross-sectional study. International Journal of Nursing Studies. 2011; 48(5):620-627. PubMed

24. Loftin RW, Habli M, Snyder CC, Cormier CM, Lewis DF, DeFranco EA. Late Preterm Birth. Reviews in Obstetrics and Gynecology. 2010; 3(1):10-19. PubMed

25. Rosenthal L, Lobel M. Explaining racial disparities in adverse birth outcomes: unique sources of anxiety for Black American women. Social Science \& Medicine (1982) 2011; 72(6):977-983. PubMed

26. Martin JA, Osterman MJK, Sutton PD. Are preterm births on the decline in the United States? Recent data from the National Vital Statistics System. NCHS data brief. 2010 ;(39):1-8. PubMed
27. Parker V, Douglas A. Anxiety in early pregnancy: maternal neuro-endocrine-immune responses and effects. Journal of Reproductive Immunology. 2010; 85(1):86-92. PubMed

28. Martin JA, Hamilton BE, Ventura SJ, Osterman MJ, Wilson EC, Matthews T. Births: Final data for 2010. National vital statistics reports. 2012;61(1) PubMed

29. Raisanen S, Lehto SM, Nielsen HS, Gissler M, Kramer MR, Heinonen S. Risk factors for and perinatal outcomes of major depression during pregnancy: a population-based analysis during 2002-2010 in Finland. BMJ Open. 2014; 4: e004883. PubMed

[1] Pregnancy-specific anxiety (P-SA)

[2] Last Menstrual Period 